\title{
The SF36 as an outcome measure of services for end stage renal failure
}

\author{
J P Wight, L Edwards, J Brazier, S Walters, J N Payne, C B Brown
}

\begin{abstract}
Objective-To evaluate the use of the short form 36 (SF36) as a measure of health related quality of life of patients with end stage renal failure, document the results, and investigate factors, including mode of treatment, which may influence it.
\end{abstract}

Design-Cross sectional survey of patients with end stage renal failure, with the standard United Kingdom version of the SF36 supplemented by specific questions for end stage renal failure.

Setting-A teaching hospital renal unit. Subjects and methods-660 patients treated at the Sheffield Kidney Institute by haemodialysis, peritoneal dialysis, and transplantation. Internal consistency, percentage of maximal or minimal responses, SF36 scores, effect sizes, correlations between independent predictor variables and individual dimension scores of the SF36. Multiple regression analysis of the

Department of Public Health Medicine, Sheffield Health Authority, Sheffield, UK

J P Wight, senior registrar

Sheffield Kidney Institute, Northern General Hospital, Sheffield, UK

L Edwards, research nurse

Department of Health Economics

J Brazier, director

Department of Statistics

$\mathrm{S}$ Walters, statistician

Department of Public Health, School of

Health and Relaxed

Research, Sheffield, UK

J N Payne, senior lecturer

Sheffield Kidney Institute, Northern General Hospital, Sheffield, UK

C B Brown, consultant nephrologist

Correspondence to: Dr J P Wright, Department in Public Health Medicine, Wakefield Health Authority, White Rose House, West Parade, Wakefield WF1 1LT, UK.

Accepted for publication 4 August 1998
SF36 scores for the physical functioning, vitality, and mental health dimensions against treatment, age, risk (comorbidity) score, and other independent variables.

Results-A high response rate was achieved. Internal consistency was good. There were no floor or ceiling effects other than for the two "role" dimensions. Overall health related quality of life was poor compared with the general population. Having a functioning transplant was a significant predictor of higher score in the three dimensions (physical functioning, vitality, and mental health) for which multiple regression models were constructed. Age, sex, comorbidity, duration of treatment, level of social and emotional support, household numbers, and hospital dialysis were also (variably) significant predictors.

Conclusions-The SF36 is a practical and consistent questionnaire in this context, and there is evidence to support its construct validity. Overall the health related quality of life of these patients is poor, although transplantation is associated with higher scores independently of the effect of age and comorbidity. Age, comorbidity, and sex are also predictive of the scores attained in the three dimensions studied. Further studies are required to ascertain whether altering those predictor variables which are under the influence of professional carers is associated with changes in health related quality of life, and thus confirm the value of this outcome as a measure of quality of care. (Quality in Health Care 1998;7:209-221)
Keywords: end stage renal failure; health related quality of life; short form 36

\section{Introduction}

MEASURING HEALTH RELATED QUALITY OF LIFE IN END STAGE RENAL FAILURE

Although treatments for end stage renal failure are undoubtedly effective in preventing death, clinicians and commissioning authorities are increasingly concerned to monitor other relevant outcomes of treatment as measures of the quality of care provided. The advice currently available $^{12}$ focuses on laboratory measurements of biological variables that are affected by the dialysis process, reflecting the technological nature of the treatment. Patient perceived health related quality of life is another outcome which is of particular interest for several reasons.

The formal assessment of the health related quality of life of dialysis patients may bring several benefits. For patients, it may bring to light problems that are amenable to intervention. ${ }^{3}$ For providers, the recognition that health related quality of life is affected by mode and place of treatment, or other factors may lead to changes in policy about treatment. For both health service commissioners and providers information about the effect of age or comorbidity on health related quality of life may provide valuable information for difficult decisions about the level of investment in the service.

Secondly, treatment for end stage renal failure is very expensive, and will consume an increasing proportion of the healthcare budget as the numbers of patients taken on to treatment programmes continues to exceed the death rate of those on treatment. In an era of constrained resources, this raises questions as to how the outcomes of these treatments compare with alternative health interventions. To make such comparisons, we need tools to measure outcomes common to all. Quality of life related to general health as assessed by the patient is one such outcome.

Assessment of health related quality of life indicates quality of care to the extent that the care provided influences quality of life. We need, therefore, first to identify a questionnaire for the measurement of health related quality of life, and then to examine the determinants of health related quality of life as measured by that questionnaire, and establish whether or not they relate to the quality of care provided. This study evaluates the short form 36 (SF36) as a measure of the health related quality of life of patients with end stage renal failure. It will be of interest both to those who are concerned with the technical aspects of the SF36 itself, as well as renal physicians and others who are 
concerned to document the health related quality of life of these patients.

The only person truly qualified to assess a patient's health related quality of life is the patient. Studies in which doctors', nurses' and patients' assessments have been compared have shown substantial disagreement between them. ${ }^{4-6}$

\section{CHOICE OF QUESTIONNAIRE}

Many of the questionnaires used to assess health related quality of life in patients with end stage renal failure in the past ${ }^{7}$ have the disadvantages of being too long for routine use or not having been well validated. The disease specific questionnaires that have been developed $^{8-12}$ have not been well validated in large samples, and do not give results that can be compared with the general disease free population, or other patient groups. Given that the objective of treatment for end stage renal failure is to replace renal function as completely as possible, it is appropriate to use a questionnaire that is designed to measure variations in the health status of normal people. A more general questionnaire has the further advantage, at least in theory, of being sensitive to the effect of comorbidity.

\section{SF36 QUESTIONNAIRE}

The SF36 questionnaire is one such measure. ${ }^{13}$ In it, the data from 36 questions are combined to provide a measure of health related quality of life in eight dimensions. These are: physical functioning $(\mathrm{PF})$, role limitations attributable to physical problems (RP), bodily pain (BP), perception of general health $(\mathrm{GH})$, vitality (VIT), social functioning (SF), role limitations attributable to emotional problems (RE), and mental health $(\mathrm{MH})$. A score from 0 (lowest health related quality of life) to 100 (highest) is derived for each.

Its reliability and validity have been well assessed ${ }^{1415}$ and normative data exist for the general English population. ${ }^{15}{ }^{16}$ It has also been shown to be valid and acceptable to patients $<65$ years. ${ }^{17-19}$ Although it is increasingly being used as an outcome measure for patients with end stage renal failure ${ }^{30-23}$ it has not been formally assessed in this population. ${ }^{24}$

\section{ASSESSING THE USE OF THE SF36}

The assessment of the use of the SF36 in the population with end stage renal failure involves seeking answers to several questions:

- Is the questionnaire practical in terms of achieving an adequate response rate?

- Does the questionnaire have internal consistency when used in this population?

- Are there large proportions of responses being either at the minimum or maximum values possible, rendering the questionnaire useless as a discriminatory tool (floor or ceiling effects)?

- Does the questionnaire have construct validity in this population?
- How comprehensive is the questionnaire in reflecting all the aspects of health related quality of life which are important to these patients?

To assess the comprehensiveness of a general questionnaire in a specific context, it is necessary to establish whether there are other important aspects of health related quality of life which it does not cover, and which may vary independently of those aspects which are covered. This requires asking additional questions relating specifically to the symptoms of end stage renal failure, and then determining the extent to which the information gathered is independent of the results of the SF36. One way to determine this is to examine the correlation between the SF36 results and the responses to the specific questions on end stage renal failure.

A high correlation suggests that those patients who have a poor health related quality of life, as measured by the SF36, also have a quality of life which is impaired by specific symptoms of end stage renal failure, and vice versa-those whose health related quality of life as measured by the SF36 is high do not have severe symptoms of end stage renal failure. A low correlation suggests the opposite - that the severity of symptoms of end stage renal failure may be independent of health related quality of life measured by the SF36. If that were to be the case, the additional specific questions about end stage renal failure could give useful additional information. The supplementation of general questionnaires with disease specific questions has been advocated elsewhere. ${ }^{25}$

\section{STUDY OBJECTIVES}

The purpose of the work described here was:

- To evaluate the use of the SF36 by patients with end stage renal failure

- To document the health related quality of life (as measured by the SF36) of patients with end stage renal failure being treated at the Sheffield Kidney Institute

- To investigate factors, including treatment, which may influence the health related quality of life of these patients.

It was decided to investigate the use of the SF36 in patients undergoing all modes of treatment (home, hospital, and satellite unit haemodialysis, peritoneal dialysis, and transplantation) because the questionnaire may perform differently in different groups of patients. Furthermore, a comparison of the results between treatments would contribute towards establishing the construct validity of the questionnaire, and thus be of independent interest.

\section{Patients and methods}

The study was conducted in the Sheffield Kidney Institute at the Northern General Hospital, Sheffield, from April to June of 1995. The pro- 
tocol was approved by the local research ethics committee. The cooperation of the Sheffield Kidney Patients Association was sought and obtained.

Sample size calculations showed that to have an $80 \%$ chance of detecting a 10 point difference in score between treatments with a significance level of $5 \%$, it would be necessary to have between 52 and 183 patients in each group, depending on the dimension. ${ }^{26}$ It was therefore decided to study all 660 patients being treated at the time.

A questionnaire was prepared consisting of the standard United Kingdom version of the SF36, supplemented by eight questions about specific symptoms of end stage renal failure. The symptoms were chosen because they had been reported by patients to be important and because the clinicians concurred with this, and they had been incorporated by others into disease specific questionnaires. ${ }^{112728}$ The eight symptoms were: dry or itchy skin; cramps; difficulty sleeping; thirst; problems with access site; muscle wasting; nausea; and impairment of sex drive. To assess the extent to which the symptom affected quality of life, and not simply record its presence, the questions were phrased "during the past 4 weeks how much have you been bothered by ...". Respondents were asked to indicate the extent on a scale from 1 (not at all) to 6 (extremely). These questions were designed for this study, and had not been independently validated. The full questionnaire is included as an appendix.

An information sheet was provided for each patient. Completion of the questionnaire was taken as a patient's consent to participation. (This approach is endorsed by the Royal College of Physicians in its guidelines to local research ethics committees.)

DATA COLLECTION

As one of the aims of the study was to evaluate the use of the SF36 in measuring overall health related quality of life, care was taken to ensure that patients did not complete the questionnaire while undergoing dialysis, which can be a distressing experience. Furthermore, the reliability of quality of life measures may be greater if they are completed between, rather than during, dialysis treatments. ${ }^{29}$

The questionnaires were distributed by hand to hospital haemodialysis patients, with a request that they should be completed at home between treatments. They were posted, with a stamped addressed envelope, to all other patients. One reminder was sent after 4 weeks.

All other data, including age, comorbidity, adequacy of dialysis (as measured by urea kinetic modelling), and haematological and biochemical variables, were obtained from hospital records. A risk category was determined for each patient according to previously published criteria. ${ }^{30}$ This categorises patients according to age and the presence of important cardiac, respiratory, or other organ disease, diabetes, or malignancy. (The categorisation was as follows: group 1 (low risk) age $<70$, no concurrent illness; group 2 (medium risk) age $70-9$, or diabetic, or notable cardiac or pulmo- nary disease; group 3 (high risk) age $\geqslant 80$, or diabetes with age $>70$, or dysfunction of $\geqslant 2$ organs as well as end stage renal failure, or malignancy (excluding skin cancers).) The risk categories have been shown to be significant predictors of survival in patients with end stage renal failure. Comparisons were made with age and sex matched controls from the general population of Sheffield, using data collected for a previous study. ${ }^{15}$ Age (within 5 year age bands) and sex matched cases were chosen at random.

\section{STATISTICAL ANALYSIS}

Data were entered on to a personal computer. Statistical tests were performed with SPSS for Windows. Because of the non-normal distribution of most of the data, the Kruskal-Wallis test was used when comparing the dimension scores between treatments, and the Wilcoxon matched pairs signed ranks test when comparing the scores of patients and age and sex matched controls. To compare patients and controls the effect size (the difference between means divided by the SD of the control group) was calculated for each dimension (this has the advantage of showing the size of the signal (the difference in scores) in comparison with the noise (the variability in score - that is, the SD). By convention, an effect size of $0.2-0.5$ is small, $0.5-0.8$ moderate, and $\geqslant 0.8$ is large. ${ }^{31}$

The scoring of the questions specific to the condition (1-6) was reversed so that lower scores indicated a more severely impaired quality of life, to be consistent with the SF36 dimension scores. To measure the correlations between them, both sets of data were treated as ordinal, and the correlation measured with the Kendall's tau- $b$ coefficient.

The relation between independent factors and health related quality of life was explored by looking at the correlations between variables and the SF36 dimension scores, and by multiple regression analysis. Firstly the Spearman rank correlation coefficients for cross correlation between the individual dimensions of the SF36, correlations between the independent variables and the individual dimension scores, and cross correlation between the independent variables, were calculated.

Any obvious non-linear relations were then sought by examining scatterplots of the individual dimension scores and the independent variables. None were detected. Multiple regression models were then constructed. To reduce the likelihood of spurious significant relations being discovered (type 1 errors), and because the different dimensions of functioning were highly correlated with each other, as were the wellbeing dimensions, further analysis was restricted to the three dimensions physical functioning, vitality, and mental health. Dummy variables were created for each type of treatment, sex, and history of previous transplantation. Missing data were deleted from the list, and the entry of variables into the model was determined stepwise, with a $p$ value for entry of 0.05 and for removal of 0.1 . Residuals were examined for normality and the absence of any trend in value (the prime assumptions for multiple 
Table 1 Demographic data (n (\%))

\begin{tabular}{|c|c|c|c|c|c|c|}
\hline & Total & Home & Hosp & $P D$ & Sat & $T x$ \\
\hline \multicolumn{7}{|l|}{ Sex: } \\
\hline Male & $312(60)$ & $29(69.0)$ & $56(56.0)$ & $62(56.9)$ & $24(58.5)$ & $141(61.8)$ \\
\hline Female & $208(40)$ & $13(31.0)$ & $44(44.0)$ & $47(43.1)$ & $17(41.5)$ & $87(38.2)$ \\
\hline Total & 520 & 42 & 100 & 109 & 41 & 228 \\
\hline \multicolumn{7}{|l|}{ Age (y): } \\
\hline$<19$ & $5(1.0)$ & $0(0.0)$ & $0(0.0)$ & $0(0.0)$ & $0(0.0)$ & $5(2.2)$ \\
\hline $20-29$ & $39(7.5)$ & $4(9.5)$ & $4(4.0)$ & $6(5.5)$ & $2(4.9)$ & $23(10.1)$ \\
\hline $30-39$ & $84(16.2)$ & $9(21.4)$ & $13(13.0)$ & $15(13.8)$ & $5(12.2)$ & $42(18.4)$ \\
\hline $40-49$ & $92(17.7)$ & $9(21.4)$ & $15(15.0)$ & $15(13.8)$ & $2(4.9)$ & $51(22.4)$ \\
\hline $50-59$ & $135(26.0)$ & $16(38.1)$ & $23(23.0)$ & $27(24.8)$ & $10(24.4)$ & $59(25.9)$ \\
\hline $60-69$ & $113(21.7)$ & $4(9.5)$ & $28(28.0)$ & $27(24.8)$ & $12(29.3)$ & $42(18.4)$ \\
\hline $70-79$ & $49(9.4)$ & $0(0.0)$ & $17(17.0)$ & $18(16.5)$ & $9(22.0)$ & $5(2.2)$ \\
\hline$>80$ & $3(0.6)$ & $0(0.0)$ & $0(0.0)$ & $1(0.9)$ & $1(2.4)$ & $1(0.4)$ \\
\hline Total & 520 & 42 & 100 & 109 & 41 & 228 \\
\hline \multicolumn{7}{|l|}{ Duration of treatment $(y)$ : } \\
\hline $0-4$ & $250(48.1)$ & $13(31.0)$ & $66(66.0)$ & $92(84.4)$ & $25(61.0)$ & $64(28.1)$ \\
\hline $5-9$ & $124(23.8)$ & $13(31.0)$ & $20(20.0)$ & $10(9.2)$ & $10(24.4)$ & $71(31.1)$ \\
\hline $10-14$ & $66(12.7)$ & $9(21.4)$ & $9(9.0)$ & $5(4.6)$ & $4(9.8)$ & $39(17.1)$ \\
\hline $15-19$ & $40(7.7)$ & $4(9.5)$ & $4(4.0)$ & $0(0.0)$ & $1(2.4)$ & $31(13.6)$ \\
\hline $20-24$ & $22(4.2)$ & $2(4.8)$ & $0(0.0)$ & $1(0.9)$ & $1(2.4)$ & $18(7.9)$ \\
\hline $25-29$ & $8(1.5)$ & $1(2.4)$ & $1(1.0)$ & $1(0.9)$ & $0(0.0)$ & $5(2.2)$ \\
\hline Total & 520 & 42 & 100 & 109 & 41 & 228 \\
\hline \multicolumn{7}{|l|}{ Comorbidity: } \\
\hline Diabetes & $66(12.7)$ & $0(0.0)$ & $11(11.0)$ & $24(22.0)$ & $8(19.5)$ & $23(10.1)$ \\
\hline $\begin{array}{l}\text { Cardiac and pulmonary } \\
\text { disease }\end{array}$ & $115(22.1)$ & $9(21.4)$ & $30(30.0)$ & $28(25.7)$ & $13(31.7)$ & $35(15.4)$ \\
\hline Other organ failure & $1(0.2)$ & $0(0.0)$ & $1(1.0)$ & $0(0.0)$ & $0(0.0)$ & $0(0.0)$ \\
\hline Malignancy & $15(2.9)$ & $0(0.0)$ & $4(4.0)$ & $7(6.4)$ & $0(0.0)$ & $4(1.8)$ \\
\hline
\end{tabular}

Home=home haemodialysis patients; Hosp=hospital haemodialysis patients; PD=peritoneal dialysis patients; Sat=satellite haemodialysis patients; $\mathrm{Tx}=$ transplanted patients.

regression). In every model these assumptions were met.

The higher SF36 scores for patients who had had a transplant compared with those who had had dialysis raised the possibility that the determinants of their quality of life are different. Three sets of multiple regression models were constructed, one for all patients combined, one for patients on dialysis, and one for transplanted patients only.

\section{Results}

CHARACTERISTICS OF THE POPULATION AND RESPONSE RATES

From the 660 patients surveyed, 520 responses $(78.8 \%)$ were returned. There was no difference in response rate between treatments, sex, or district of residence. Nor was there any difference in the age, duration of treatment, or distance travelled to treatment between responders and non-responders. Fewer than 2\% of patients required assistance in completing the questionnaire, assistance which was provided by an experienced dialysis nurse recruited for the study.

Ethnic minorities make up about $5 \%$ of the patients treated at the Sheffield Kidney Institute. Ethnicity was therefore not analysed further. The characteristics of the patients studied are given in table 1 .
EVALUATION OF THE USE OF THE SF36 IN PATIENTS WITH END STAGE RENAL FAILURE Acceptability of the questionnaire

The high response rate, and informal comments from patients, gives an indication, albeit limited, that the questionnaire was acceptable to most of them. Some commented that it took longer than the estimated 10-15 minutes to complete.

Internal consistency

Cronbach's $\alpha$ was $>0.8$ for each dimension except social functioning, for which the overall value was 0.72 (table 2). In this dimension it was 0.79 for transplanted patients, and 0.60 for dialysis patients.

Floor and ceiling effects

The percentage of minimal (a score of 0 , floor) or maximal responses (a score of 100, ceiling) are also shown in table 2. For all except the "role physical" and "role emotional" dimensions responses are spread across the range of possible results. Similar results were obtained when each treatment was examined separately (data not shown).

\section{Comprehensiveness}

The distribution of responses (for all patients combined) to the specific questions about end stage renal failure was in each case heavily

Table 2 Dimensions of quality of life

\begin{tabular}{|c|c|c|c|c|c|c|c|c|}
\hline & $\begin{array}{l}\text { Physical } \\
\text { function }\end{array}$ & $\begin{array}{l}\text { Role } \\
\text { physical }\end{array}$ & $\begin{array}{l}\text { Bodily } \\
\text { pain }\end{array}$ & $\begin{array}{l}\text { General } \\
\text { health }\end{array}$ & Vitality & $\begin{array}{l}\text { Social } \\
\text { functioning }\end{array}$ & $\begin{array}{l}\text { Role } \\
\text { emotional }\end{array}$ & $\begin{array}{l}\text { Mental } \\
\text { health }\end{array}$ \\
\hline Subjects (n) & 514 & 492 & 517 & 499 & 517 & 518 & 489 & 514 \\
\hline Cronbach's $\alpha$ & 0.95 & 0.93 & 0.91 & 0.83 & 0.86 & 0.72 & 0.90 & 0.82 \\
\hline Median & 45 & 0 & 66.7 & 40 & 45 & 55.6 & 66.7 & 71.3 \\
\hline Interquartile range & $20-80$ & $00-100$ & $33.3-100$ & $22-62$ & $25-60$ & $33.3-88.9$ & $0-100$ & $55.3-84.0$ \\
\hline $\begin{array}{l}\text { Responses at lowest } \\
\text { possible score }(\%)\end{array}$ & 4.9 & 50.8 & 3.5 & 1.8 & 4.5 & 5.4 & 34.4 & 0.4 \\
\hline $\begin{array}{l}\text { Responses at highest } \\
\text { possible score }(\%)\end{array}$ & 6.8 & 28.7 & 26.5 & 2.0 & 0.8 & 22.9 & 47.0 & 4.7 \\
\hline
\end{tabular}



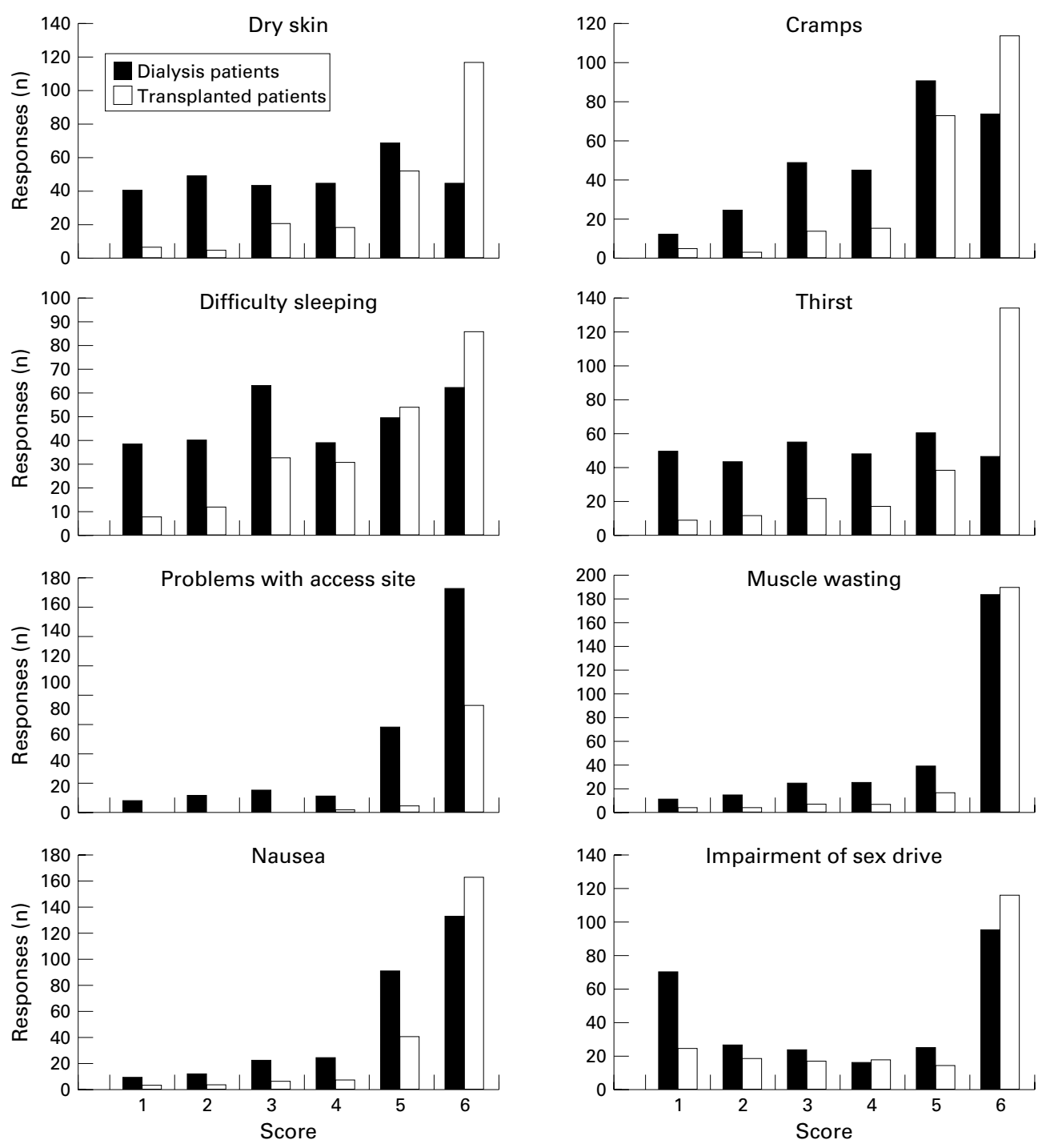

\begin{tabular}{|c|c|c|c|c|c|c|c|c|}
\hline \multirow[b]{2}{*}{ Response } & \multicolumn{8}{|c|}{ Number of responses in each response category, for each question. } \\
\hline & Dry skin & Cramps & Sleeping & Thirst & Access site & $\begin{array}{l}\text { Muscle } \\
\text { wasting }\end{array}$ & Nausea & Sex drive \\
\hline \multicolumn{9}{|l|}{ Dialysis: } \\
\hline 6 & 41 & 12 & 39 & 47 & 8 & 8 & 7 & 71 \\
\hline 5 & 50 & 24 & 40 & 42 & 12 & 12 & 11 & 26 \\
\hline 4 & 43 & 48 & 63 & 53 & 15 & 23 & 22 & 24 \\
\hline 3 & 44 & 44 & 38 & 46 & 12 & 25 & 23 & 17 \\
\hline 2 & 69 & 89 & 49 & 58 & 66 & 39 & 89 & 25 \\
\hline 1 & 44 & 72 & 61 & 43 & 171 & 181 & 181 & 95 \\
\hline \multicolumn{9}{|c|}{ Transplantation: } \\
\hline 6 & 7 & 5 & 7 & 8 & 0 & 2 & 3 & 26 \\
\hline 5 & 5 & 2 & 11 & 10 & 0 & 2 & 3 & 18 \\
\hline 4 & 22 & 13 & 32 & 20 & 1 & 5 & 6 & 17 \\
\hline 3 & 18 & 15 & 30 & 15 & 1 & 6 & 6 & 18 \\
\hline 2 & 51 & 71 & 54 & 36 & 3 & 17 & 40 & 14 \\
\hline 1 & 117 & 114 & 86 & 131 & 81 & 188 & 162 & 116 \\
\hline
\end{tabular}

Distribution of responses to specific questions about end stage renal failure by dialysis and transplanted patients. The response categories 1-6 indicate increasing impairment of quality of life by the symptom. Each diagram shows the number of patients returning that response for that symptom.

skewed towards the higher scores. Thus it is clear that the symptoms asked about did not interfere greatly with the quality of life of the most patients. However, when the responses of dialysis and transplanted patients are analysed separately, as shown in the figure, the responses for dialysis patients are less skewed towards higher scores for the questions relating to dry skin, cramps, difficulty sleeping, and thirst. This suggests that for these patients, these particular questions do discriminate between some patients for whom these symptoms do interfere with their quality of life, and others for whom this is not the case. 
Table 3 Mean (SD) score for each dimension for all patients and each treatment group, together with the scores for the relevant age and sex matched control group, the effect size, and the p value for the difference between patients and age and sex matched controls with the Wilcoxon matched pairs signed ranks test

\begin{tabular}{|c|c|c|c|c|c|c|c|c|}
\hline Mean & $\begin{array}{l}\text { Physical } \\
\text { function }\end{array}$ & $\begin{array}{l}\text { Role } \\
\text { physical }\end{array}$ & $\begin{array}{l}\text { Bodily } \\
\text { pain }\end{array}$ & $\begin{array}{l}\text { General } \\
\text { health }\end{array}$ & Vitality & $\begin{array}{l}\text { Social } \\
\text { functioning }\end{array}$ & $\begin{array}{l}\text { Role } \\
\text { emotional }\end{array}$ & $\begin{array}{l}\text { Mental } \\
\text { health }\end{array}$ \\
\hline \multicolumn{9}{|l|}{ All: } \\
\hline Mean & 48.5 & 37.4 & 61.3 & 42.9 & 43.4 & 60.4 & 56.0 & 68.3 \\
\hline Control & 82.2 & 78.8 & 77.5 & 69.5 & 58.4 & 88.0 & 82.5 & 74.2 \\
\hline $\mathrm{SD}$ (control) & 23.6 & 35.8 & 24.3 & 21.6 & 13.0 & 21.4 & 33.2 & 19.1 \\
\hline $\begin{array}{l}\text { Effect size } \\
\text { p Value }\end{array}$ & 1.43 & 1.16 & 0.67 & 1.23 & 1.15 & 1.29 & 0.80 & 0.31 \\
\hline \multicolumn{9}{|l|}{ Home: } \\
\hline Mean & 47.1 & 40.9 & 54.7 & 38.1 & 41.7 & 62.9 & 65.0 & 68.8 \\
\hline Control & 86.3 & 84.8 & 80.8 & 74.4 & 61.6 & 87.3 & 82.9 & 76.6 \\
\hline SD (control) & 22.3 & 31.6 & 25.1 & 24.0 & 10.7 & 24.8 & 34.3 & 18.7 \\
\hline Effect size & 1.75 & 1.39 & 1.04 & 1.51 & 1.86 & 0.98 & 0.52 & 0.42 \\
\hline $\mathrm{p}$ Value & & & 0.0006 & & 0.0001 & 0.0007 & 0.0630 & 0.1318 \\
\hline \multicolumn{9}{|l|}{ Hosp: } \\
\hline Mean & 33.6 & 23.6 & 48.6 & 31.6 & 34.5 & 41.9 & 31.0 & 60.0 \\
\hline Control & 79.3 & 74.2 & 76.9 & 67.0 & 56.3 & 85.8 & 76.4 & 73.0 \\
\hline $\mathrm{SD}$ (control) & 24.5 & 38.0 & 23.9 & 21.4 & 13.2 & 23.2 & 36.8 & 18.3 \\
\hline $\begin{array}{l}\text { Effect Size } \\
\text { p Value }\end{array}$ & 1.86 & 1.33 & 1.19 & 1.66 & 1.65 & 1.89 & 1.23 & 0.71 \\
\hline \multicolumn{9}{|l|}{ PD: } \\
\hline Mean & 40.6 & 20.4 & 59.0 & 35.1 & 35.8 & 50.0 & 55.5 & 65.9 \\
\hline Control & 81.5 & 81.4 & 76.4 & 70.9 & 59.3 & 90.3 & 83.8 & 75.6 \\
\hline SD (control) & 23.7 & 34.6 & 24.5 & 21.3 & 12.2 & 28.8 & 32.6 & 18.3 \\
\hline $\begin{array}{l}\text { Effect size } \\
\text { p Value }\end{array}$ & 1.73 & 1.76 & 0.71 & 1.68 & 1.93 & 1.40 & 0.87 & $\begin{array}{l}0.53 \\
0.0004\end{array}$ \\
\hline \multicolumn{9}{|l|}{ Sat: } \\
\hline Mean & 28.3 & 16.7 & 55.3 & 31.6 & 32.0 & 48.8 & 29.7 & 66.6 \\
\hline Control & 74.4 & 67.9 & 73.3 & 64.5 & 61.7 & 85.9 & 87.0 & 77.9 \\
\hline SD (control) & 28.8 & 42.3 & 26.7 & 21.9 & 14.6 & 22.1 & 31.2 & 15.8 \\
\hline Effect size & 1.60 & 1.21 & 0.68 & 1.50 & 2.04 & 1.68 & 1.84 & 0.71 \\
\hline $\mathrm{p}$ Value & & 0.0002 & 0.0080 & & & & 0.0001 & 0.0026 \\
\hline \multicolumn{9}{|l|}{ Tx: } \\
\hline Mean & 62.5 & 53.5 & 70.2 & 54.3 & 53.2 & 75.2 & 68.8 & 73.2 \\
\hline Control & 84.4 & 80.1 & 78.4 & 69.8 & 57.7 & 88.5 & 83.4 & 73.0 \\
\hline SD (control) & 22.2 & 34.8 & 23.8 & 21.3 & 13.3 & 21.4 & 32.0 & 20.4 \\
\hline Effect size & 0.99 & 0.76 & 0.34 & 0.73 & 0.33 & 0.62 & 0.46 & -0.01 \\
\hline $\mathrm{p}$ Value & & & 0.0031 & & 0.0597 & & & 0.6959 \\
\hline
\end{tabular}

Where the $\mathrm{p}$ value is not given it is $<0.0001$.

Home=home haemodialysis patients; Hosp=hospital haemodialysis patients; PD=peritoneal dialysis patients; Sat=satellite haemodialysis patients; $\mathrm{T} x=$ transplanted patients.

As a test of whether the extra questions were giving useful extra information about the health related quality of life of these patients, the correlation coefficients between the SF36 dimension scores and the responses to the extra questions were calculated. When all patients were included, correlations overall were moderate. The greatest correlation was between the social functioning dimension and thirst (Kendall's tau- $b=0.38$ ), and the least between the mental health dimension and impairment of sex drive (tau- $b=0.18$ ).

Because the skew in responses to these questions was largely attributable to the transplanted patients, correlation coefficients were calculated for dialysis and transplanted patients separately. For transplanted patients the coefficients were still moderate, ranging from 0.38 (social functioning and difficulty sleeping) to 0.11 (role emotional and access). However, for dialysis patients the coefficients were lower, the greatest being 0.30 , between bodily pain and difficulty sleeping. In 10 cases the significance of the correlation was $<0.01$ $(\mathrm{p}>0.01)$.

The fact that there was less correlation between the responses to extra questions and the SF36 dimensions for dialysis than for transplanted patients indicates that, in these patients, the additional questions were more useful in detecting extra information, and by inference the SF36 was less comprehensive.
HEALTH RELATED QUALITY OF LIFE OF PATIENTS WITH END STAGE RENAL FAILURE

The mean scores for each SF36 dimension for all patients and each treatment group, together with scores of the age and sex matched controls, and the differences between each treatment group and age and sex matched controls as measured by the effect sizes, are shown in table 3. The mean scores for all patients with end stage renal failure combined were lower than the control group on every dimension.

Transplanted patients scored higher than other treatment groups on every dimension, but not as high as control patients. Patients on hospital and satellite haemodialysis tended to score lower than those on peritoneal dialysis or home haemodialysis patients. The differences between treatments were highly significant for all eight dimensions (Kruskal-Wallis $\mathrm{p}<0.0001$ ). When transplanted patients were excluded the differences between remaining treatments were significant $(p<0.01)$ only for the physical functioning, role physical, social functioning and role emotional dimensions. (In the other dimensions, the difference in scores was $\leqslant 10.4$ points. Given the size of the subgroups, the study did not have the power to detect differences of this magnitude.)

Effect sizes for the patients on dialysis were large for all except the mental health dimension (all dialysis modalities), role emotional in home dialysis patients, and bodily pain in the peritoneal and satellite dialysis patients. For the 
Table 4 Spearman rank correlation coefficients between independent variables and the individual dimension scores

\begin{tabular}{|c|c|c|c|c|c|c|c|c|c|c|}
\hline & Age (y) & Risk score & Duration & Distance & Travel time & $\begin{array}{l}\text { Social and } \\
\text { emotional } \\
\text { support }\end{array}$ & Haemoglobin & Albumin & $\begin{array}{l}\text { Total } \\
\text { protein }\end{array}$ & Sex \\
\hline Physical functioning & -0.46 & -0.36 & 0.11 & -0.31 & -0.29 & 0.05 & 0.33 & 0.29 & 0.26 & -0.19 \\
\hline Role physical & -0.31 & -0.29 & 0.18 & -0.24 & -0.24 & 0.05 & 0.28 & 0.28 & 0.23 & -0.05 \\
\hline Bodily pain & -0.20 & -0.15 & -0.01 & -0.20 & -0.19 & 0.09 & 0.22 & 0.19 & 0.19 & -0.06 \\
\hline General health & -0.16 & -0.24 & 0.10 & -0.27 & -0.26 & 0.15 & 0.38 & 0.30 & 0.24 & -0.07 \\
\hline Vitality & -0.27 & -0.23 & 0.13 & -0.24 & -0.23 & 0.02 & 0.32 & 0.28 & 0.25 & -0.10 \\
\hline Social functioning & -0.23 & -0.28 & -0.21 & -0.31 & -0.30 & 0.11 & 0.33 & 0.31 & 0.26 & -0.09 \\
\hline Role emotional & -0.24 & -0.20 & -0.17 & -0.31 & -0.30 & 0.20 & 0.18 & 0.19 & 0.17 & -0.04 \\
\hline Mental health & -0.05 & -0.12 & 0.10 & -0.20 & -0.17 & 0.23 & 0.21 & 0.15 & 0.16 & -0.11 \\
\hline
\end{tabular}

Risk=risk category (see text); Duration=duration of end stage renal failure treatment $(\mathrm{y})$; Distance $=$ distance travelled for treatment; Travel time $=$ time taken to travel for treatment; Social and emotional support=self assessed level of social and emotional support; Albumin=serum albumin; Total protein=serum total protein.

transplanted patients, effect sizes were small or moderate for all except the physical functioning dimension. The $\mathrm{p}$ value for the differences in dimension scores between treatment and control groups were $<0.01$ (Wilcoxon matched pairs signed ranks test) for all except vitality and mental health scores in the transplanted patients, and role emotional and mental health in the patients on home dialysis.

RELATION BETWEEN INDEPENDENT VARIABLES, INCLUDING TREATMENTS, AND SF36 SCORES A high correlation was found between the dimension scores. Specifically, the different physical dimensions were highly correlated with each other (physical functioning $v$ role physical, $r_{s}=0.61$ ), as were the mental/emotional dimensions (mental health $v$ role emotional, $\left.r_{s}=0.52\right)$. However, correlation between physical and mental dimensions was less (physical functioning $v$ mental health, $r_{s}=0.35$ ).

Details of correlations between independent variables and the dimensions of the SF36 are given in table 4 . There was no correlation between dimension scores and: household numbers, previous transplantation, distance travelled, district of residence, adequacy of dialysis, and biochemical measures other than serum albumin and total protein (serum sodium, potassium, bicarbonate, creatinine, urea, phosphate, calcium, and alkaline phosphatae).

Some of the independent variables (as expected) were highly correlated with one another, in particular, distance travelled and travel time $\left(r_{s}=0.95\right)$, and serum albumin and total protein levels $\left(r_{s}=0.80\right)$.

MULTIPLE REGRESSION MODELS

The models may be summarised as formulas as shown in the box. Independent variables appear in each formula in order of significance. Variables that do not appear were not significantly associated with that dimension score in that model. Full details of model characteristics are shown in table 5 .

\section{Discussion}

EVALUATION OF THE USE OF THE SF36

Although the SF36 is increasingly being used in patients treated for end stage renal failure, ${ }^{320-23}$ its use in this population has not previously been formally assessed.

\footnotetext{
Models may be summarised as follows:

FOR ALL PATIENTS

Physical functioning $=97-0.75$ (age) +19.57 (transplant) -10.87 (female) -7.62 (risk) 0.04 (duration)

Vitality $=39+8.90$ (transplant) -0.33 (age) $+1.59(\mathrm{Hb})-4.57$ (risk) +1.87 (social and emotional support) -1.43 (household numbers)

Mental health $=60+4.72$ (transplant) +2.79 (social and emotional support) -6.57 (hospital)

-4.57 (female) -2.86 (risk)

FOR PATIENTS ON DIALYSIS ONLY

Physical functioning $=80-0.41$ (age) -11.37 (female) -8.44 (risk) -0.10 (travel time)

Vitality $=33-6.27$ (risk) -5.64 (female) $+1.43(\mathrm{Hb})$

Mental health $=30-6.89$ (hospital dialysis) +2.14 (social and emotional support) +0.50 (albumin)

FOR TRANSPLANTED PATIENTS ONLY

Physical functioning $=98-1.28$ (age) -8.80 (female) $-2.09(\mathrm{Hb})$

Vitality $=-3.8-0.60$ (age) +3.60 (social and emotional support) $+1.69(\mathrm{Hb})+0.61$ (total protein)

Mental health $=52+4.14$ (social and emotional support) Where: age $=$ age $(\mathrm{y})$; transplant $=1$ for transplant patients, 0 for others; female $=1$ for women, 0 for men; risk $=$ risk category ${ }^{30}$; duration $=$ duration of treatment $(\mathrm{y}) ; \mathrm{Hb}=$ haemoglobin in $\mathrm{g} / \mathrm{dl}$; hospital dialysis $=1$ for patients on hospital dialysis, 0 for all others; travel time = travel time in minutes; Albumin = serum albu$\min$ in $\mathrm{g} / \mathrm{l}$; total protein $=$ serum total protein in $\mathrm{g} / \mathrm{l}$.
} 
Table 5 Summary of values of B (standard error of B) for predictive variables and model characteristics for the multiple regression models

\begin{tabular}{|c|c|c|c|c|c|c|c|c|c|}
\hline \multirow[b]{3}{*}{ Variables in the equation } & \multicolumn{9}{|c|}{ Dependent variable } \\
\hline & \multicolumn{3}{|c|}{ Physical functioning } & \multicolumn{3}{|l|}{ Vitality } & \multicolumn{3}{|l|}{ Mental health } \\
\hline & All patients & Dialysis only & Transplants & All patients & Dialysis only & Transplants & All patients & Dialysis only & Transplants \\
\hline Age (y) & $-0.75(0.09)$ & $-0.41(0.12)$ & $-1.27(0.13)$ & $-0.33(0.08)$ & & $-0.60(0.11)$ & & & \\
\hline Transplant & $19.57(2.64)$ & & & $8.90(2.68)$ & & & $4.72(1.96)$ & & \\
\hline Sex & $-10.87(2.40)$ & $-11.37(3.11)$ & $-9.80(3.79)$ & & $-5.64(2.55)$ & & $-4.57(1.75)$ & & \\
\hline Haemoglobin & & & $2.09(0.94)$ & $1.59(0.53)$ & $1.43(0.71)$ & $1.69(0.79)$ & & & \\
\hline Risk & $-7.62(2.06)$ & $-8.44(2.52)$ & & $-4.57(1.75)$ & $-6.27(1.88)$ & & $-2.86(1.39)$ & & \\
\hline Hospital dialysis & & & & & & & $-6.57(2.43)$ & $-6.89(2.42)$ & \\
\hline $\begin{array}{l}\text { Social and emotional } \\
\text { support }\end{array}$ & & & & $1.87(0.76)$ & & $3.60(1.27)$ & $2.79(0.65)$ & $2.14(0.83)$ & $4.14(1.07)$ \\
\hline Household number & & & & $-1.91(0.79)$ & & & & & \\
\hline Albumin & & & & & & & & $0.50(0.21)$ & \\
\hline Total protein & & & & & & $0.61(0.30)$ & & & \\
\hline Travel time & & $-0.10(0.05)$ & & & & & & & \\
\hline Duration & $-0.04(0.02)$ & & & & & & & & \\
\hline Adjusted $R^{2}$ & 0.33 & 0.17 & 0.31 & 0.19 & 0.06 & 0.16 & 0.10 & 0.05 & 0.06 \\
\hline$F$ & 52.03 & 15.27 & 35.44 & 21.22 & 7.38 & 11.63 & 12.60 & 6.36 & 14.90 \\
\hline Significanee of $F$ & $<0.0001$ & $<0.0001$ & $<0.0001$ & $<0.0001$ & $=0.0001$ & $<0.0001$ & $<0.0001$ & $=0.0003$ & $=0.0001$ \\
\hline $\mathrm{n}$ & 520 & 292 & 228 & 520 & 292 & 228 & 520 & 292 & 228 \\
\hline
\end{tabular}

A high response rate was obtained. Internal consistency was shown by values of Cronbach's $\alpha>0.8$ for seven of the eight dimensions. It is possible that the low figure for the social functioning dimension arises as a result of the patients' health providing the rationale for such social activities as they have on the dialysis unit. The lower value for dialysis than transplant patients supports this supposition.

There are no floor or ceiling effects, other than for the role dimensions. This has been reported previously in renal patients, ${ }^{320}$ and in general populations, ${ }^{15}$ and so may indicate an inherent flaw in the questionnaire. These dimensions derive from questions about "problems with work or other regular daily activities", which may not be appropriate for chronically ill people, or elderly people, ${ }^{18}$ who are unlikely to be in work.

Evidence of construct validity comes from the comparison of scores with those of a general population, and the better scores obtained by transplant patients. The lower correlation between the SF36 dimension scores and the responses to the additional specific questions about renal failure in dialysis patients suggests that there are domains of health related quality of life that are important in these patients, and which may not be covered by the questionnaire.

HEALTH RELATED QUALITY OF LIFE OF PATIENTS BEING TREATED FOR END STAGE RENAL FAILURE Overall, scores do not compare well with the general population. The difference between the patients on dialysis and controls varies, but averages over 30 points - which is greater than the difference between 65-74 year olds and 25-34 year olds in the general population. ${ }^{15}$ (Most of the $\mathrm{p}$ values for these comparisons are $<0.0001$, rendering the likelihood of type 1 errorsattributing a real difference where none existsextremely unlikely.) Effect sizes were smaller for the mental than physical dimensions (as in the only other study to quote effect $\operatorname{size}{ }^{23}$ ), and there was also less difference in scores between treatments in these dimensions.

Comparisons may also be made with other chronic conditions. ${ }^{32}$ These patients had better scores for vitality and mental health, and simi- lar scores for physical functioning, compared with a group of patients with low back pain. They also scored higher in mental health and vitality than patients with menorrhagia and higher in mental health than patients with suspected peptic ulcer. Patients with varicose veins scored higher in all these dimensions.

RELATION BETWEEN TREATMENT AND INDIVIDUAL DIMENSION SCORES

The presence of a functioning transplant remained a significant predictor of improved health related quality of life scores, even when age, haemoglobin, and comorbidity (risk score) were taken into account in the multiple regression models. As transplantation obviates the need for dialysis, this is not a surprising finding, and is in keeping with other studies. ${ }^{33-39}$

Hospital dialysis was significantly negatively associated with mental health score, even when other predictive factors were taken into account. It is not possible to say from this study whether there is a causal relation between hospital dialysis and poor mental health score, nor the direction of any causation. However patients on hospital dialysis, of all the groups studied, have the least control over their own treatment, which may contribute to the lower score. ${ }^{40-43}$

None of the other three treatments (home dialysis, satellite dialysis, and peritoneal dialysis) were significant predictors of the scores. Thus, any differences between these groups are explained by the different case mix. This finding differs from that of some other investigators. $^{3644}$

OTHER PREDICTIVE FACTORS

Age emerges as the most important predictor of physical functioning score for all patients, as well as when dialysis and transplant patients were analysed separately. It is also a predictor of vitality score in transplanted patients and in patients as a whole, but not when the analysis is restricted to dialysis patients. It is not a predictive factor for the mental health scores in either subgroup or in all patients-indicating that there is no reduction in mental health score with age. All these observations, including the magnitude of decline in physical functioning 
score with age, are similar to findings in the general population. ${ }^{15}$ Thus, other things being equal, and in particular in the absence of notable comorbidity, there is no greater decline in health related quality of life of patients with end stage renal failure than in the general population. Further, the independence of mental health score from age suggests that older patients with end stage renal failure are just as well adjusted psychologically as younger ones. These findings will lend further weight to demands that more older people merit dialysis.

Sex is a significant predictor of physical functioning in both subgroups and in all patients. It is also a predictor of vitality in dialysis patients, and mental health score for all patients, (but not for each subgroup). (In all cases men scored higher than women.) The difference in physical functioning score between sexes is greater in these patients than in the normal 55-64 year age group. ${ }^{15}$ We can only speculate as to the reasons for this. It may be that whereas men on renal replacement therapy are cared for by their wives or other family members, women are less supported, and further may not themselves perform the normal female supportive roles. This merits further research.

Risk score was a significant predictor for physical functioning and vitality in patients on dialysis, and for all three treatments when all patients were combined. This is not surprising in view of the way risk categories are determined. ${ }^{30}$ It adds value to this simple scoring system, which predicts mortality in patients with end stage renal failure both before ${ }^{45}$ and after $^{3046}$ starting dialysis. However, many patients had other comorbidities not included within this score, which will have contributed to the residual variance. It was not a predictor in the transplanted patients. Self assessed social and emotional support was a significant predictor of vitality score (transplanted patients and all patients) and mental health score (both subgroups and all patients).

It would be unwise to overinterpret the other independent variables that are predictive in single models, given the multiple comparisons that have been made. The fact that haemoglobin concentration does not seem to be a good predictor of SF36 score in the multiple regression models (other than for vitality, and even there the effect is modest), is perhaps surprising, in view of the documented effect of erythropoietin induced increases in haemoglobin on quality of life. ${ }^{47}$ This may be explained by the fact that many of the patients studied were being treated with erythropoietin, so that the haemoglobin concentrations did not vary greatly.

Adequacy of dialysis was not related to quality of life scores, a finding that replicates other studies. ${ }^{23} 4950$ Similarly, distance from the treatment centre, history of transplantation, ${ }^{51}$ marital status, ${ }^{810}$ and district of residence did not bear any relation to any of the three dimensions of quality of life examined.

The overall predictive power of these models was modest. The model with physical functioning as the dependent variable, with all patients, achieved the highest adjusted $R^{2}$, and even in this case it was only 0.33 , indicating that only just $33 \%$ of the variability in score was explained by the independent variables examined. For the other dimensions, in particular the mental health score, the figure was much less, indicating that $<10 \%$ of the variability could be explained by the model. These findings are similar to those of another study in which the links between various predictive factors and SF36 scores were explored. ${ }^{23}$

\section{Conclusions}

The SF36 is a practical and consistent questionnaire for measuring the health related quality of life of transplanted and dialysis patients, although some caution is needed in interpreting the scores of emotional and physical roles. There is support for its validity. However there are domains of health related quality of life of these patients, particularly those on dialysis, which are not assessed by this questionnaire.

Overall, the results indicate that health related quality of life is poor, and worse in physical than in mental and emotional dimensions. Improved scores achieved by transplanted patients persist even when other possible explanatory variables are taken into account. Health related quality of life is no more affected by age in the population with end stage renal failure than in the general population, but the quality of life enjoyed by female patients does seem to be worse than that of male patients. The level of comorbidity remains an important predictor.

Health related quality of life reflects quality of care to the extent that factors which influence quality of life are amenable to intervention by professional carers. The observed correlations reported here cannot be taken to indicate causality. That can only be shown by intervention studies-for example providing increased levels of social support to determine whether this affects the mental health score. These findings should help to inform the designers of such studies, and so eventually lead to improved quality of care and quality of life for patients with end stage renal failure.

We thank the patients who completed the questionnaires, and all the staff on the Renal Unit at the Northern General Hospital and the satellite units for their help with completing this study. Funding for this work was from the former Trent Regional Health Authority Research and Development Programme. LE
is supported by the Sheffield Kidney Research Fund.

1 Greenwood RN, Aldridge C, Farrington K, et al. Quality standards in dialysis: advice to purchasers. Times Health standards in dialysis: advice
Supplement May 1992:7-12.

2 Treatment of adult patients with renal failure. London: The Renal Association and the Royal College of Physicians, 1995.

3 Meyer KB, Espindle DM, DeGiacomo JM, et al. Monitoring dialysis patients' health status. American fournal of Kidney Diseases 1994;24:267-79.

4 Slevin ML, Plant H, Lynch D, et al. Who should measure quality of life, the doctor or patient? $\mathrm{Br} \mathcal{F}$ Cancer 1988;57:09-112.

5 Meers C, Hopman W, Singer MA, et al. A comparison of patient, nurse and physician assessment of health related patient, nurse and physician assessment of health related plantation 1995;4:120-4,139.

plantation 1995;4:120-4, 139.
Molzahn AE, Northcott HC, Dossetor JB. Quality of life of individuals with end stage renal disease: perceptions of individuals with end stage renal disease: perceptions of
patients, nurses, and physicians. American Nephrology Nurses Association fournal 1997;24:325-33. 
7 Milner PC. The choice of quality of life outcome measure in a randomised clinical trial of twice versus thrice weekly haemodialysis. London: Faculty of Public Health cine, 1987. (Report no 3 of MFCM Part II submission 1987.)

8 Ferrans CE, Powers MJ. Quality of life of hemodialysis patients. American Nephrology Nurses Association fournal 1993;20:575-82

9 Laupacis A, Muirhead N, Keown P, et al. A disease specific questionnaire for assessing quality of life in patients on haemodialysis. Nephron 1992;60:302-6.

10 Park H, Bang WR, Kim SJ, et al. Quality of Life of ESRD patients: development of a tool and comparison between transplant and dialysis patients. Transplant Proc 1992;24: 1435-7.

11 Hays RD, Kallich JD, Mapes DL, et al. Development of the kidney disease quality of life (KDQOLTM) instrument. Oual Life Res 1994:3:329-38.

12 Salek S. Quality of life assessment in patients on peritoneal dialysis: a review of the state of the art. Perit Dial Int 1996; 16(suppl 1):S398-401.

13 Ware JE. Measuring patients' views: the optimum outcome measure. BMF 1993;306:429-30.

14 Outcomes Briefing Issue 4. Leeds: UK Clearing House for Health Outcomes, Nuffield Institute for Health, 1994

15 Brazier JE, Harper R, Jones NMB, et al. Validating the SF-36 health survey questionnaire: new outcome measure for primary care. $B M \mathcal{F} 1992 ; 305: 160-4$.

16 Jenkinson C, Coulter A, Wright L. Short form 36 health survey questionnaire: normative data for adults of working age. BMF 1993;306:1437-40.

17 Lyons RA, Pery HM, Littlepage BNC. Evidence for the validity of the short form 36 questionnaire (SF-36) in an elderly population. Age Ageing 1994;23:182

18 Hayes V, Morris J, Wolfe C, et al. The SF-36 health survey questionnaire: is it suitable for use with older adults? Age Ageing 1995;24:120-5.

19 Singleton N, Turner A. SF-36 is suitable for elderly patients. BMF 1993;307:126-7.

20 Kurtin PS, Davis AR, Meyer KB, et al. Patient based health status measures in outpatient dialysis: early experiences in developing an outco

21 Khan IH, Garratt AM, Kumar A, et al. Patients' perception of health on renal replacement therapy: evaluation using a new instrument. Nephrol Dial Transplant 1995;10:684-9.

22 Rettig RA, Sadler JH, Meyer KB, et al. Assessing health and quality of life outcomes in dialysis: a report on an institute of medicine workshop. Am f Kidney Dis 1997;30:140-55.

23 Merkus MP, Jager KJ, Dekker FW, et al. Quality of life in patients on chronic dialysis: self assessment 3 months after the start of treatment. Am f Kidney Dis 1997;29:584-92.

24 Welch G. Assessment of quality of life following renal failure. In: McGee H, Bradley C, eds Ouality of life following renal failure. Switzerland: Harwood Academic, 1994.

25 Gill TM, Feinstein AR. A critical appraisal of the quality of quality of life measurements. FAMA 1994;272:619-26.

26 Ware JE, Snow KK, Kosinski M, et al. SF-36 health survey manual and interpretation guide. Boston, MA: New England Medical Centre, The Health Institute, 1993.

27 Laupacis A, Muirhead N, Keown P, et al. A disease specific questionnaire for assessing quality of life in patients on haemodialysis. Nephron 1992;60:302-6.

28 Parfrey PS, Vavasour H, Bullock M, et al. Development of a health questionnaire specific for end stage renal disease. Nephron 1989;52:20-8.

29 Badia X, Alonso J, Brosa M, et al. Reliability of the Spanish version of the Nottingham health profile in patients with stable end stage renal disease. Soc Sci Med 1994;38:153-8.
30 Wright L. Survival in patients with end-stage renal disease. Am 7 Kidney Dis 1991;17:25-8.

31 Cohen J. Statistical power analysis for the behavioural sciences. New York: Academic Press, 1978.

32 Garratt AM, Ruta DA, Abdalla MI, et al. The short form 36 health survey questionnaire: an outcome measure suitable for routine use within the NHS? BMF 1993;306:1440-4.

33 Hart LG, Evans RW. The functional status of ESRD patients as measured by the sickness impact profile. f Chron Dis 1987; 40 (suppl 1):117S-30S.

34 Churchill DN, Morgan J, Torrance GW. Quality of life in end stage renal disease. Peritoneal Dialysis Bulletin 1984; 20-3.

35 Morris PLP, Jones B. Transplantation versus dialysis: a study of quality of life. Transplant Proc 1988;20:23-6.

36 Churchill DN, Torrance GW, Taylor DW, et al. Measurement of quality of life in end stage renal disease: the time trade off approach. Clin Invest Med 1987;10:14-20.

37 Kaplan De-Nour A, Shanan J. Quality of life of dialysis and transplanted patients. Nephron 1980;25:117-20.

38 Evans RW, Mannien DL, Garrison LP, et al. The quality of life of patients with end stage renal disease. $N$ Engl $\mathcal{F}$ Med 1985;312:553-9.

39 Russell DJ, Beecroft ML, Ludwin D, et al. The quality of life in renal transplantation: a prospective study. Transplantation 1992;54:656-60.

40 Devins GM, Binik YM, Hutchinson TA, et al. The emotional impact of end stage renal disease: importance of patients perceptions of intrusiveness and control. Int f Psypatients perceptions of intrusive
chiatry Med 1984;13:327-43.

41 Bremer BA, Haffly D, Fox RM, et al. Patients' perceived control over their health care: an outcome assessment of their psychological adjustment to renal failure. $\mathrm{Am} \mathcal{F} \mathrm{Med}$ Qual 1995;10:149-54.

42 Szabo E, Moody H, Hamilton T, et al. Choice of treatment improves quality of life. A study of patients undergoing dialysis. Arch Intern Med 1997;157:1352-6.

43 Meers C, Singer MA, Toffelmire EB, et al. Self-delivery of haemodialysis care: a therapy in itself. Am $\mathcal{F}$ Kidney Dis 1996;27:844-7.

44 Simmons RG, Abress L. Quality of life issues of end stage renal failure patients. Am F Kidney Dis 1990;15:201-8.

45 Khan IH, Catto GRD, Edward N, et al. Chronic renal failure: factors influencing nephrology referral. $Q \mathcal{f ~} \mathrm{Med}$ 1994;87:559-64.

46 Khan IH, Catto GRD, Edward N, et al. Influence of coexisting disease on survival on renal-replacement therapy. Lancet 1993;341:415-8.

47 Canadian Erythropoietin Study Group. Association between recombinant human erythropoietin and quality of life and exercise capacity of patients receiving haemodialysis. BMF 1990;300:573-8.

48 Auer J, Simon G, Stevens J, et al. Quality of life improvements in CAPD patients treated with subcutaneously administered erythropoietin for anaemia. Perit Dial Int 1992;12:40-2.

49 Steele TE, Baltimore D, Finkelstein SH, et al. Quality of life in peritoneal dialysis patients. F Nerv Mental Dis 1996;184: in perito

50 Ross Morton A, Meers C, Singer MA, et al. Quantity of dialysis: quality of life: what is the relationship? ASAIO $\mathcal{f}$ 1996:42.M713-7.

51 McCauley C, Johnson JP. Transplantation failure: psychosocial consequences and their management. In: McGee $\mathrm{H}$, Bradley C, eds. Quality of life following renal failure. Switzerland: Harwood Academic, 1994. 
Appendix 1

CONFIDENTIAL

\section{SHEFFIELD HEALTH AUTHORITY}

SHEFFIELD KIDNEY INSTITUTE

\section{A survey of renal patients' views about their own health.}

The answers you give to these questions will be kept confidential, and the information will not be used in any way that could identify you.

Enclosed are a series of questions asking you what you think and feel about your own health. At the end there are some questions which provide us with background information. Please give an answer to every question.

NAME

HOSPITAL NUMBER .................

HEALTH STATUS QUESTIONNAIRE (SF-36)

The following questions ask for your views about your health, how you feel and how well you are able to do your usual activities.

If you are unsure about how to answer a question, please give the best answer you can and make any comments in the space available on page 10 .

1. In general, would you say your health is:

\begin{tabular}{|c|c|}
\hline & (circle one) \\
\hline Excellent. & 1 \\
\hline Very good & 2 \\
\hline . & 3 \\
\hline …...................... & 4 \\
\hline … & 5 \\
\hline
\end{tabular}

2. Compared to one year ago, how would you rate your health in general now?

Much better than one year ago ...............

Somewhat better than one year ago........ 2

About the same .................................. 3

Somewhat worse now than one year ago.. 4

Much worse now than one year ago

\section{HEALTH AND DAILY ACTIVITIES}

3. The following questions are about activities that you might do during a typical day. Does your health limit you in these activities? If so, how much?

(circle one number on each line)

\begin{tabular}{|l|c|c|c|}
\hline ACTIVITIES & $\begin{array}{l}\text { Yes, } \\
\text { limited } \\
\text { a lot }\end{array}$ & $\begin{array}{l}\text { Yes, } \\
\text { limited } \\
\text { a little }\end{array}$ & $\begin{array}{l}\text { No, not } \\
\text { limited } \\
\text { at all }\end{array}$ \\
\hline $\begin{array}{l}\text { a. Vigorous activities, such as } \\
\text { running, lifting heavy objects, } \\
\text { participating in strenuous sports }\end{array}$ & 1 & 2 & 3 \\
\hline $\begin{array}{l}\text { b. Moderate activities, such as moving } \\
\text { a table, pushing a vacuum cleaner, } \\
\text { bowling or playing golf }\end{array}$ & 1 & 2 & 3 \\
\hline c. Lifting or carrying groceries & 1 & 2 & 3 \\
\hline d. Climbing several flights of stairs & 1 & 2 & 3 \\
\hline e. Climbing one flight of stairs & 1 & 2 & 3 \\
\hline f. Bending, kneeling or stooping & 1 & 2 & 3 \\
\hline g. Walking more than a mile & 1 & 2 & 3 \\
\hline h. Walking half a mile & 1 & 2 & 3 \\
\hline
\end{tabular}

4. During the past 4 weeks, have you had any of the following problems with your work or other regular daily activities as a result of your physical health?

(circle one number on each line)

\begin{tabular}{|l|c|c|}
\hline $\begin{array}{l}\text { a. Cut down on the amount of time you spent } \\
\text { on work or other activities }\end{array}$ & 1 & 2 \\
\hline $\begin{array}{l}\text { b. Accomplished less than you would like } \\
\text { C. Were limited in the kind of work or other } \\
\text { activities }\end{array}$ & 1 & 2 \\
\hline $\begin{array}{l}\text { d. Had difficulty in performing the work or } \\
\text { other activities (e.g. it took extra effort) }\end{array}$ & 1 & 2 \\
\hline
\end{tabular}

5. During the past 4 weeks, have you had any of the following problems with your work or other regular daily activities as a result of any emotional problems (such as feeling depressed or anxious)?

(circle one number on each line)

\begin{tabular}{|l|c|c|}
\hline $\begin{array}{l}\text { a. Cut down on the amount of time you spent } \\
\text { on work or other activities }\end{array}$ & 1 & 2 \\
\hline b. Accomplished less than you would like & 1 & 2 \\
\hline $\begin{array}{l}\text { c. Didn't do work or other activities as } \\
\text { carefully as usual }\end{array}$ & 1 & 2 \\
\hline
\end{tabular}


6. During the past 4 weeks, to what extent has your physical health or emotional problems interfered with your normal social activities with family, friends, neighbours or groups?

\begin{tabular}{|c|c|}
\hline 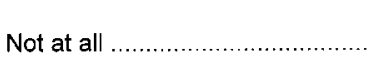 & $\begin{array}{l}\text { (circle one } \\
1\end{array}$ \\
\hline Slightly ............................ & 2 \\
\hline Moderately. & 3 \\
\hline Quite a bit & 4 \\
\hline Extremely. & 5 \\
\hline
\end{tabular}

7. How much bodily pain have you had during the past 4 weeks?

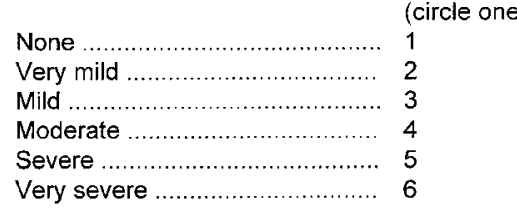

8. During the past 4 weeks, how much did pain interfere with your normal work (including work both outside the home and housework)?

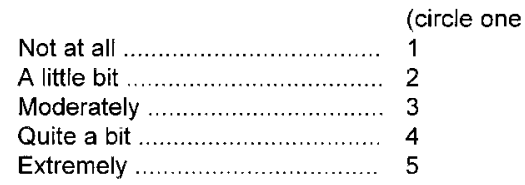

YOUR FEELINGS

9. These questions are about how you feel and how things have been with you during the past 4 weeks. (For each question, please indicate the one answer that comes closest to the way you have been feeling.)

\begin{tabular}{|l|c|c|c|c|c|c|}
\hline \multicolumn{5}{|c|}{ (circle one number on each line) } \\
\begin{tabular}{|l} 
time much of the \\
during the past 4 \\
weeks:
\end{tabular} & $\begin{array}{l}\text { All of } \\
\text { the } \\
\text { time }\end{array}$ & $\begin{array}{l}\text { Most } \\
\text { of the } \\
\text { time }\end{array}$ & $\begin{array}{l}\text { A good } \\
\text { bit of } \\
\text { the } \\
\text { time }\end{array}$ & $\begin{array}{l}\text { Some } \\
\text { of the } \\
\text { time }\end{array}$ & $\begin{array}{l}\text { A } \\
\text { little } \\
\text { of the } \\
\text { time }\end{array}$ & $\begin{array}{l}\text { None } \\
\text { of the } \\
\text { time }\end{array}$ \\
\hline $\begin{array}{l}\text { a. Did you feel full } \\
\text { of life? }\end{array}$ & 1 & 2 & 3 & 4 & 5 & 6 \\
\hline $\begin{array}{l}\text { b. Have you been a } \\
\text { very nervous } \\
\text { person? }\end{array}$ & 1 & 2 & 3 & 4 & 5 & 6 \\
\hline $\begin{array}{l}\text { c. Have you felt so } \\
\text { down in the dumps } \\
\text { that nothing could } \\
\text { cheer you up? }\end{array}$ & 1 & 2 & 3 & 4 & 5 & 6 \\
\hline $\begin{array}{l}\text { d. Have you felt } \\
\text { calm and peaceful? }\end{array}$ & 1 & 2 & 3 & 4 & 5 & 6 \\
\hline $\begin{array}{l}\text { e. Did you have a } \\
\text { lot of energy? }\end{array}$ & 1 & 2 & 3 & 4 & 5 & 6 \\
\hline $\begin{array}{l}\text { f. Have you felt } \\
\text { down-hearted and } \\
\text { low? }\end{array}$ & 1 & 2 & 3 & 4 & 5 & 6 \\
\hline $\begin{array}{l}\text { g. Did you feel } \\
\text { worn-out? }\end{array}$ & 1 & 2 & 3 & 4 & 5 & 6 \\
\hline $\begin{array}{l}\text { h. Have you been a } \\
\text { happy person? }\end{array}$ & 1 & 2 & 3 & 4 & 5 & 6 \\
\hline $\begin{array}{l}\text { i. Did you feel } \\
\text { tired? }\end{array}$ & 1 & 2 & 3 & 4 & 5 & 6 \\
\hline $\begin{array}{l}\text { j. Has your health } \\
\text { visiting friends or relatives) }\end{array}$ & 1 & 2 & 3 & 4 & 5 & 6 \\
\hline
\end{tabular}

10. Please choose the answer that best describes how true or false each of the following statements is for you?

(circle one number on each line)

\begin{tabular}{|l|c|c|c|c|c|}
\hline & $\begin{array}{l}\text { Definitely } \\
\text { true }\end{array}$ & $\begin{array}{l}\text { Mostly } \\
\text { true }\end{array}$ & $\begin{array}{l}\text { Not } \\
\text { sure }\end{array}$ & $\begin{array}{l}\text { Mostly } \\
\text { false }\end{array}$ & $\begin{array}{l}\text { Definitely } \\
\text { false }\end{array}$ \\
\hline $\begin{array}{l}\text { a. I seem to get } \\
\text { ill more easily } \\
\text { than other } \\
\text { people }\end{array}$ & 1 & 2 & 3 & 4 & 5 \\
\hline $\begin{array}{l}\text { b. I am as } \\
\text { healthy as } \\
\text { anybody I know }\end{array}$ & 1 & 2 & 3 & 4 & 5 \\
\hline $\begin{array}{l}\text { c. I expect my } \\
\text { health to get } \\
\text { worse }\end{array}$ & 1 & 2 & 3 & 4 & 5 \\
\hline $\begin{array}{l}\text { d. My health is } \\
\text { excellent }\end{array}$ & 1 & 2 & 3 & 4 & 5 \\
\hline
\end{tabular}

\section{SUPPLEMENTARY QUESTIONS RELATING TO RENAL SYMPTOMS}

11. During the past 4 weeks how much have you been bothered by itching or dry skin?

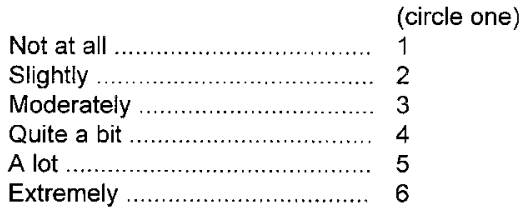

12. During the past 4 weeks how much have you been bothered by cramps?

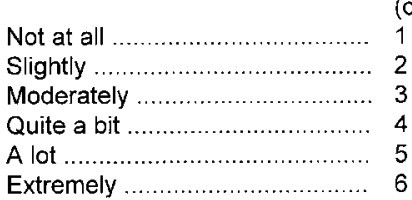

13. During the past 4 weeks how much have you been bothered by difficulty sleeping?

\begin{tabular}{|c|c|}
\hline \multicolumn{2}{|c|}{ 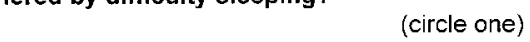 } \\
\hline Not at all ... & 1 \\
\hline Slightly ... & 2 \\
\hline Moderately & 3 \\
\hline Quite a bit & 4 \\
\hline 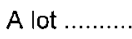 & 5 \\
\hline Extremely. & 6 \\
\hline
\end{tabular}

14. During the past 4 weeks how much have you been bothered by thirst, a dry mouth, or difficulty with fluid balance?

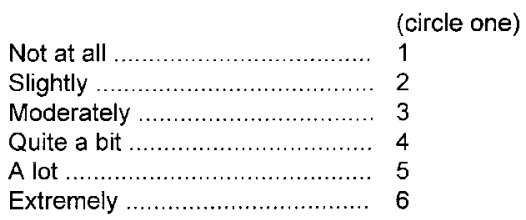

15. During the past 4 weeks how much have you been bothered by problems with your needling site (for haemodialysis patients) or catheter exit site (for CAPD patients)?

\begin{tabular}{|c|c|}
\hline \multicolumn{2}{|c|}{ one) } \\
\hline Not at all & 1 \\
\hline Slightly ... & 2 \\
\hline Moderately & 3 \\
\hline Quite a bit . & 4 \\
\hline A lot ........... & 5 \\
\hline Extremely .. & 6 \\
\hline
\end{tabular}


16. During the past 4 weeks how much have you been bothered by loss of weight or muscle?

\begin{tabular}{|c|c|}
\hline & (circle one) \\
\hline Not at all. & 1 \\
\hline 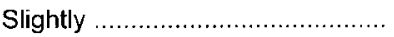 & 2 \\
\hline Moderately .... & 3 \\
\hline 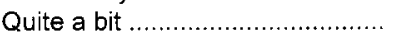 & 4 \\
\hline 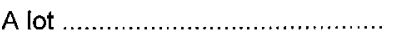 & 5 \\
\hline 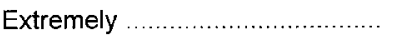 & 6 \\
\hline
\end{tabular}

17. During the past 4 weeks how much have you been bothered by nausea?

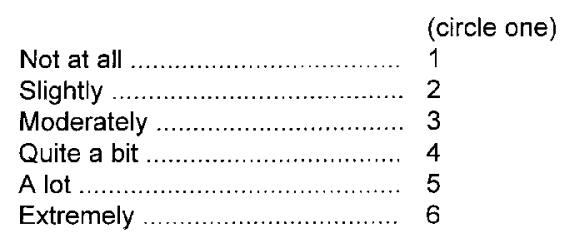

18. During the past 4 weeks how much have you been bothered by impotence or lack of sex drive?

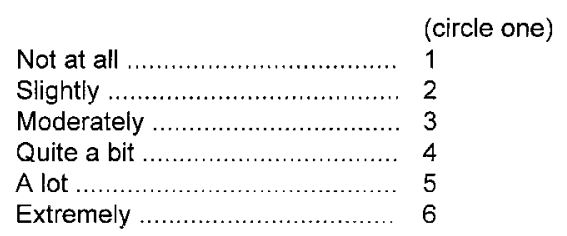

\section{AND NOW SOME BACKGROUND QUESTIONS}

19. How long does it take you to travel from home to where you have treatment (please give the total time, including waiting time, for a journey one way).

Time taken to get from home to treatment..........hrs........mins.
20. How many people live in your household, including you?............

21. What is your marital status?

\begin{tabular}{ll} 
Single................................... & 1 \\
\hline Married / long term relationship & 2 \\
Divorced / seperated............... & 3 \\
Widowed................................ & 4
\end{tabular}

22. Which of the following statements most accurately describes the amount of social and emotional support you have at home, from family and friends?

(circle one)

$\begin{array}{ll}\text { I have none at all .................... } & 1 \\ \text { I have very little support ............ } & 2 \\ \text { I have some support .............. } & 3 \\ \text { I have quite a bit of support ...... } & 4 \\ \text { I have a lot of support .............. } & 5 \\ \text { I have an awful lot of support .... } & 6\end{array}$

23. Are there any other symptoms or aspects of your life that have affected your quality of life over the last four weeks?

3

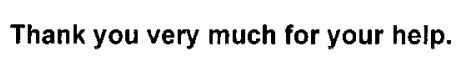

